\title{
Nymphoplasty Plus Lipotransference of the Labia Majora in Female Genital Cosmetic Surgery
}

\section{Tamayo Carbon $\mathrm{AM}^{1}$, Vila Garcia $\mathrm{E}^{2 *}$, Abreu Corniel $\mathrm{RA}^{3}$ and Orozco Jaramillo MA ${ }^{4}$}

${ }^{1}$ Specialists of II degree in Plastic Surgery and Caumatology, Surgical Hospital Hermanos Ameijeiras, Cuba

${ }^{2}$ Specialist I degree in General Surgery, Surgical Hospital Hermanos Ameijeiras, Cuba ${ }^{3}$ Specialists of I degree in General Surgery and 4th year Resident of Plastic Surgery and Caumatology, Surgical Hospital Hermanos Ameijeiras, Cuba ${ }^{4} 3$ rd year Resident of Plastic Surgery and Caumatology, Surgical Hospital Hermanos Ameijeiras, Cuba

*Corresponding author: Eyleen Vila Garcia, Assistant Professor, Services of Plastic Surgery and Caumatology and General Surgery, Surgical Hospital Hermanos Ameijeiras, Havana City, Cuba, Tel: 53232327; email: hielenvg@infomed.sld.cu

\section{Abstract}

Introduction: Nymphoplasty plus lipotransference of the labia majora is a technique of female genital cosmetic surgery of the vulva, which involves the removal of a portion of the hypertrophic labia minora and an augmentation of the labia majora. Objective: To evaluate the results of nymphoplasty with lipotransference of the labia majora for the treatment of hypertrophy of the labia minora.

Method: An observational, descriptive, longitudinal and prospective study was carried from January 2017 to June 2019 of 25 patients with hypertrophy of the labia minora who attended the Reconstructive Surgery and Caumatology Service of the "Hermanos Ameijeiras" Surgical Hospital. All of them underwent female genital cosmetic surgery with nymphoplasty technique plus lipotransference of the labia majora.

Results: The average age was $40.8 \pm 5.7$ years and the most frequent clinical manifestation was local irritation in 19 women. The only reported complication was severe edema in one patient. Good surgical results predominated as well as the good state of satisfaction of the patients in 24 cases.

Conclusions: Nymphoplasty with lipotransference of the labia majora offers good surgical results, few complications and a high degree of satisfaction for the patients.

Keywords: Genitalia; Nymphoplasty; Lipotransference

\section{Introduction}

The constant evolution of Plastic Surgery and its development in the body reconstruction of the female genital area, allow raising the self-esteem and intimacy of women, by beautifying this area. There is a contemporary cultural preference for having small lips, some women seek to have vulvas where the labia minora are completely hidden by the labia majora, in adolescents this is due to the immaturity of the female sexual apparatus [1].

Hypertrophy of the labia minora was originally described as bulging tissue that protrudes beyond the labia majora. In 1983 Friedrich defined the maximum width between 


\section{International Journal of Transplantation \& Plastic Surgery}

the midline and the lateral free edge of the labia minora at no more than $5 \mathrm{~cm}$. Others have suggested that the normal width of the labia minora should be less than $3-4 \mathrm{~cm}[1,2]$.

The cause is unknown. However, in some cases it occurs after androgen administration during childhood, in women who have sexual intercourse at an early age or who masturbate frequently. It is also described in female cyclists and a genetic component can rarely exist. Another cause of lip hypertrophy may be secondary to infection by filaria sanguinis hominis, which causes a blockage of the lymphatic ducts and causes lip lymphedema. This condition is also observed in patients with neurogenic bladder, considering that chronic inflammation of the genitals through urine and contact with diapers may be the cause [2-4].

The symptomatology of this pathology is diverse. It manifests with local irritation, discomfort when walking or sitting, and problems related to personal hygiene during menstruation. Local disorders can increase their intensity in activities that compress the vulva such as: walking, running, riding a bicycle or horse, etc. In some women, it causes them not to have sexual intercourse due to fear of showing their vulva, while in others it can cause dyspareunia due to friction of the labia minora in the vaginal introitus during intercourse. In women affected with neurogenic bladder, the difficulty in performing intermittent catheterization is added. As a consequence of all these symptoms, psychological disorders arise that affect the quality of life of the patients [5].

There are many surgical techniques and their variants for the treatment of hypertrophy of the labia minora. Most seek aesthetic results with a low incidence of complications and an acceptable degree of patient satisfaction. The most commonly used are: wedge ninfectomy with or without a 90 - Z-plasty, reduction with de-epithelialized nymphoplasty, the Trim technique and the Wedge or $\mathrm{V}$ technique. Complications that occur in these cosmetic surgeries of the female genital area are: excessive bleeding, severe edema, wound dehiscence or infection, poor healing and urinary retention [3-7].

These techniques are indicated in patients with hypertrophic lesser lip greater than $4 \mathrm{~cm}$ and with asymmetric edges, secondary to congenital conditions, chronic irritation or excessive androgenic stimulation. In recent years, the number of women concerned about the appearance of their external genitalia and in particular hypertrophic labia minora has increased. This is because they cause major anatomical problems, psychological damage and other symptoms that are exacerbated during physical activity and affect the quality of life. Different surgical techniques are used to treat this problem. However, there are no studies evaluating its results. This motivated this research with the aim of evaluating the results of nymphoplasty of the labia minora with lipotransference of the labia majora in female genital cosmetic surgery for the treatment of hypertrophy of the labia minora [8].

\section{Method}

An observational, descriptive, longitudinal, and prospective study was carried from January 2017 to June 2019 of 25 women diagnosed with hypertrophy of the labia minora treated female genital cosmetic surgery with combined technique of nymphoplasty plus lipotransference of the labia majora in the Plastic Surgery Service of the "Hermanos Ameijeiras" Hospital. Healthy patients were included between 19 and 60 years of age, diagnosed with hypertrophy of the labia minora, who gave their consent to participate in the study. Patients with gynecological neoplastic disease, active vaginal infection, decompensated chronic diseases, harmful habits and decompensated psychiatric diseases were excluded.

Consultation and Preoperative Indications: In the consultation with the patients who gave their consent, preoperative paraclinical studies and anesthetics were indicated.Surgical treatment, benefits, possible complications were explained and the data collection form was prepared. A photographic record was also made and outpatient surgery was indicated after breakfast and cleaning of the genital region with iodized water or aqueous hibitane.

\section{Surgical Technique}

Partial Nymphoplasty: The incision begins at the glans of the clitoris just below where the labia minora divide and ends where they fuse into the tissue a short distance from the hairpin. This curved incision leaves a lesser lip that has a maximum width of $1 \mathrm{~cm}$, and a free border that is pink and not pigmented. However, in normal women with small labia minora, the free edges of the lips are not pigmented very often. The lips are sutured with interrupted stitches or continuous suture with a 4.0 colorless absorbable thread. Does not require special postoperative care [4].

Combination partial nymphoplasty plus lipotransference of the labia majora: Patient in a gynecological position, antisepsis and asepsis of the anterior wall of the abdomen, thighs and external genitalia, local anesthesia is infiltrated in the labia minora and the same is resected. The partial nymphoplasty technique infiltrates Klein's solution in the area to be liposucted (usually the lower hemiabdomen or internal aspect of both thighs), liposuction is performed, the fatty tissue is decanted, a minimum access incision is made at the border anterior of both labia majora and lipograft is performed until a symmetry is achieved in both labia majora, 


\section{International Journal of Transplantation \& Plastic Surgery}

with superior projection to the labia majora and a volume up to $30 \mathrm{ml}$, in harmony with their physical build.

Postoperative care: From the immediate postoperative it is indicated: antibiotic prophylaxis, analgesia, daily washing of the wound area, avoids pressing the operated area with sitting position or tight clothing and symptomatic treatment. Outpatient surgery was performed and they were directed to reevaluate in consultation at 4 days, one month and 6 months with control photographs.

Evaluation of the aesthetic results of the surgical treatment: The results are evaluated according to the surgical parameters:

- Good: If there is improvement in the genital aspect (labia minora $\leq 2 \mathrm{~cm}$, projection of the labia majora that surpasses the minors plus symmetry), disappearance of symptoms and absence of complications.

- Regular: If only two of the elements described above are presented.

- Bad: If only one of the above parameters is presented or none of them.

\section{Analysis and Processing of Information}

From the data collected in spreadsheets, an Excel database of the Windows 10 operating system and with the SPSS (Stadistical Pachage for Social Sciences) version 18.0 for Windows is created. For the analysis of the information, descriptive statistical measures appropriate for this study were used. Variables are summarized in absolute numbers and proportions, expressed as percentages. The age variable was also summarized as mean, as a measure of central tendency, and standard deviation, as measure of dispersion. The results are presented in figures.

\section{Results}

In the study, the age range of 31 to 40 years with 15 women predominated, followed by the age group between 19 and 30 years with 6 patients and then the ages between 41 and 50 years with 4 cases.

Graph 1 shows the clinical manifestations of the patients, with local irritation prevailing with $76 \%$ and discomfort with underwear in $72 \%$.

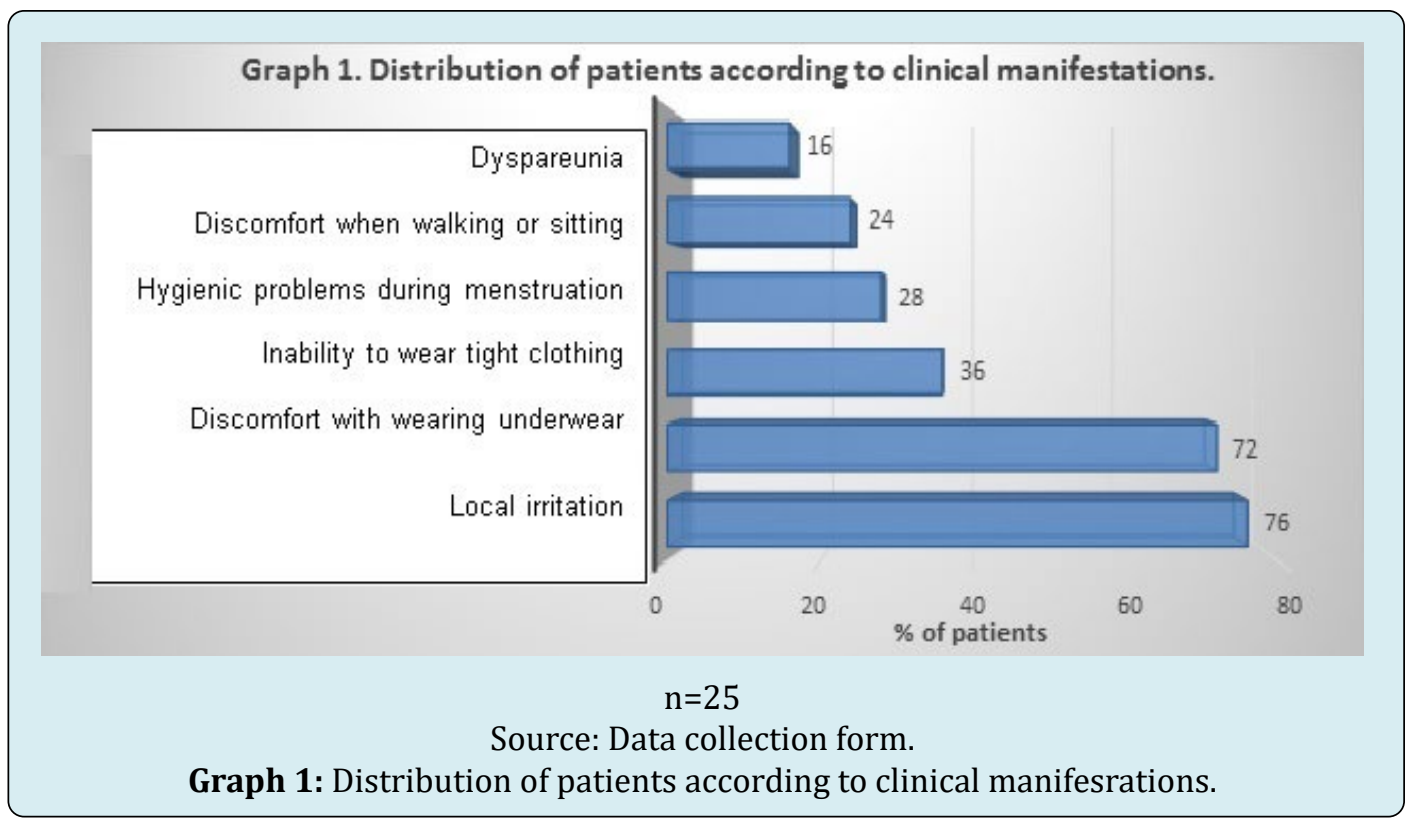

Surgical parameters show a good result in $96 \%$ of cases, with improvement of the genital aspect characterized by labia minora $\leq 2 \mathrm{~cm}$, projection of the labia majora superior to the minors plus symmetry; (Figures 1 and 2) the symptoms disappeared and without complications. Only one patient in the study complicated with severe edema of the labia minora for not complying with the surgeon's postoperative indications, and a regular surgical result was obtained with $4 \%$.
In the present study, the combination of nymphoplasty plus lipotransference of the labia majora provides good results, both aesthetic and functional, and a low rate of complications, making it a good choice in the treatment of hypertrophy of the labia minora.

The degree of satisfaction of the patients with the surgery was high in $96 \%$ of results and expectations, which favored them in the aesthetic, functional and psychological aspects. 


\section{International Journal of Transplantation \& Plastic Surgery}

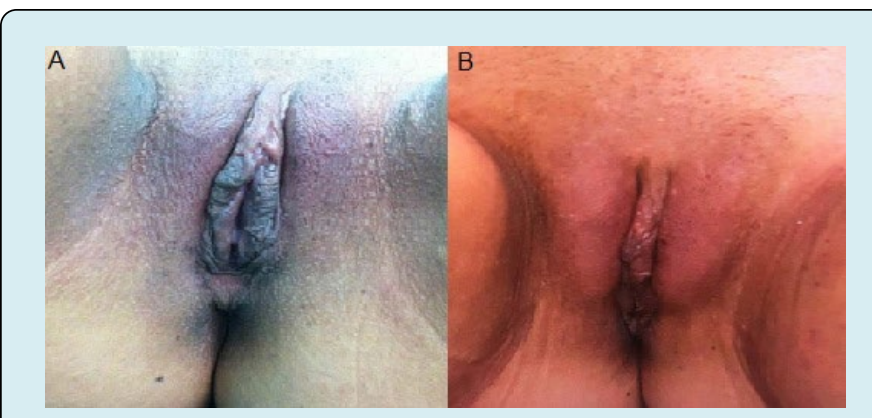

Figure 1: A: Preoperative. B: 1- year Postoperative.

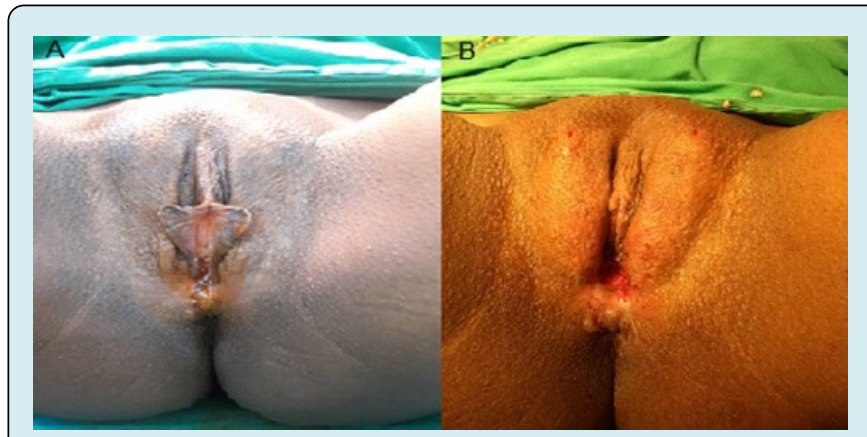

Figure 2: A: Preoperative. B: 1- year Postoperative.

No case was reoperated.

\section{Discussion}

The most affected age groups are similar to the study by Pardo et al., Where the age groups that mostly requested surgery were between 20 to 39 years old. This result also agrees with other authors that the average age was 40 years. The literature highlights that regardless of the age of the woman, the reduction of the labia minora is necessary, due to the impact it has on her self-esteem, body self-image or functional discomfort due to the size of her labia minora [5,913].

Similar clinical manifestations are observed in the study by Runacre, et al. It is suggested that the most common manifestations are: irritation in the vulvar region, discomfort with the use of underwear, the impossibility of using tight clothing or swimsuits, and difficulty in performing exercises such as cycling and horse riding due to pain during practice. In the study presented by Kruk-Jeromin and collaborator, $43.5 \%$ of the cases presented hypertrophy, which caused hygienic problems during the menstrual period and discomfort when wearing tight clothes and sitting for $56.8 \%$ and $21.9 \%$ respectively $[4-6,15]$.

Women with hypertrophic or prominent labia minora have clinical manifestations of functional and psychosocial disorders. When the labia minora protrude markedly from the labia majora, it causes local irritation, hygienic difficulties, discomfort when walking or playing sports, and interferes with the normal development of sexuality [16-18].

The presence of one or more symptoms is an indication for nymphoplasty. It is also performed for aesthetic purposes when the labia minora are present that affect self-esteem, but not the development of the intimate and daily life of the woman. In this case, the sole objective of the surgery is to improve the overall appearance of the vulva and the patient's relationship with her body $[17,18]$.

In this study, no patient had to be reoperated, unlike two case series that reported surgical reoperation rates between 2.9 and $7 \%$, due to wound dehiscence and nonconformity with the aesthetic result. Arda had a similar immediate complication bleeding in a patient Triana and col. This study presents superior results when compared with that of Hexsel, et al. Who reported in $9 \%$ of cases $(n=44)$ a mild to moderate suture dehiscence, which was treated conservatively, spontaneously closing the lesion $[3,9,11,19]$.

The American College of Obstetricians and Gynecologists (ACOG) highlights the safety and effectiveness of genital cosmetic surgery, based on reported clinical data. He has pointed out that all female genital surgery, including nymphoplasty, can present postoperative complications such as: alteration of the sensitivity of the genitals, dyspareunia, scars and decreased sexual satisfaction, none of these complications were presented in this investigation. Both efficacy and safety, after nymphoplasty surgery plus lipotransference, have been demonstrated despite all kinds of controversies; since the satisfaction rate is significantly high [20-22].

The degree of satisfaction of the patients with the highly satisfied surgery corresponds to that of other authors such as Goodma, et al. Jack Pardo, et al. As well as Sharp, et al. Who, in a prospective study, showed that well-indicated nymphoplasty provides excellent results. , with a high degree of improvement in self-esteem and decrease in local discomfort [5,22].

Similar results were by Iglesia and col. where high satisfaction is shown regarding the resolution of hypertrophy of the labia minora and its importance in aesthetic, functional and psychological areas; widely meeting the expectations of the patients, as well as other previously published results on this technique. Recently, Miklos, et al. In a prospective study, showed that nymphoplasty provides a decrease in local discomfort, without negatively affecting orgasm $[3,12,16]$. 


\section{International Journal of Transplantation \& Plastic Surgery}

\section{Conclusion}

Nymphoplasty plus lipotransference of the labia majora is a technique that provides good results in female genital cosmetic surgery for hypertrophy of the labia minora.

\section{References}

1. Edward J Wilkinson (1983) Vulvar Disease. $2^{\text {nd }}$ (Edn.), Philadelphia: W.B. Saunders.

2. Pardo J, Solá V, Ricci P, Guilloff E (2016) Laser labioplasty of labia minora. Int J Gynaecol Obstet 93: 38-43.

3. Miklos J, Moore R, Chinthakanan O (2014) Overall patient satisfaction scores, including sexual function, following labiaplasty surgery: A propspective study comparing women with a history of prior cosmetic surgery to those with none. Plastic \& Reconstructive Surgery 134(4S-1): 124-5.

4. Runacres SA, Wood PL (2016) Cosmetic labiaplasty in an adolescent population. J Pediatr Adolesc Gynecol 29: 218-22.

5. Ellsworth WA, Rizvi M, Lypka M, Gaon M, Smith B, et al. (2010) Techniques for labia minora reduction: an algorithmic approach. Aesthetic Plast Surg 34: 105-10.

6. Kelishadi SS, Elston JB, Rao AJ, Tutela JP, Mizuguchi NN (2013) Posterior wedge resection: a more aesthetic labiaplasty. Aesthet Surg J 33: 847-53.

7. Oranges CM, Sisti A, Sisti G (2015) Labia minora reduction techniques: a comprehensive literature review. Aesthet Surg J 35(4): 419-31.

8. Pardo J, Solá V, Galán G, Contreras L (2015) Genital labiaplasty, experience and results in 500 consecutive cases. Rev Chilena Obstet Ginecol 80(5): 394-400.

9. Hexsel D, Pop S, Rusciani A (2015) Rejuvenation of the External Female Genitalia. Surgery of the Skin. $13^{\text {th }}$ ((Edn.), eEspaña: Elsevier.

10. Chang P, Salisbury MA, Narsete T, Buckspan R, Derrick D, et al. (2013) Vaginal Labiaplasty: Defense of the Simple "Clip and Snip" and a New Classification System. Aesthetic Plast Surg 37(5): 887-891.
11. Gress S (2013) Composite Reduction Labiaplasty. Aesth Plast Surg 37(4): 674-683.

12. Lista F, Mistry BD, Singh Y, Ahmad J (2015) The Safety of Aesthetic Labiaplasty: A Plastic Surgery Experience. Aesthet Surg J 35(6): 689-695.

13. Lowenstein L, Salonia A, Shechter A, Porst H, Burri A, et al. (2014) Physicians' attitude toward female genital plastic surgery: a multinational survey. J Sex Med 11(1): 33-39.

14. Kruk-Jeromin J, Zieli?ski T (2010) Hypertrophy of labia minorapathomorphology and surgical treatment. Ginekol Pol 81: 298-302.

15. Espitia De La Hoz, FJ (2015) Unlimited Sex / The flight to a more pleasant sexuality. 1st (Edn.), Bogotá. Bolivar Publishing 2(1): 59-65.

16. Smarrito S (2014) Lambda laser nymphoplasty: retrospective study about 231 cases. Plast Reconstr Surg 133(2): 231ee232e.

17. Espitia de La Hoz FJ (2019) Effectiveness of nymphoplasty to improve sexual function in hypertrophy of the labia minora. Rev Col Plastic and Reconstructive Surgery 25(1): $37-43$

18. Triana L, Robledo AM (2015) Aesthetic surgery of female external genitalia. Aesthet Surg J 35: 165-77.

19. Committee on Gynecologic Practice, American College of Obstetricians and Gynecologists. ACOG committee opinion no. 378: vaginal "rejuvenation" and cosmetic vaginal procedures. Obstet Gynecol 2007; 110: 737-738

20. Pauls RN (2014) We are the correct physicians to treat women requesting labiaplasty. Am J Obstet Gynecol 211(3): 218.e1

21. Goodman MP (2011) Female genital cosmetic and plastic surgery: a review. J Sex Med 8: 1813-1825.

22. Sharp G, Tiggemann M, Mattiske J (2016) Factors That Influence the Decision to Undergo Labiaplasty: Media, Relationships, and Psychological Well-Being. Aesthet Surg J 36(4): 469-478. 